\title{
Comparison on Soil Carbon Stocks Between Urban and Suburban Topsoil in Beijing, China
}

\author{
LUO Shanghua $^{1}$, MAO Qizheng ${ }^{1,2}$, MA Keming ${ }^{1}$ \\ (1. State Key Laboratory of Urban and Regional Ecology, Research Center for Eco-Environmental Science, Chinese Academy of Sci- \\ ences, Beijing 100085, China; 2. Center for Human-Environment System Sustainability, Beijing Normal University, Beijing 100875, \\ China)
}

\begin{abstract}
The urban population and urbanized land in China have both increased markedly since the 1980s. Urban and suburban developments have grown at unprecedented rates with unknown consequences for ecosystem functions. In particular, the effect of rapid urbanization on the storage of soil carbon has not been studied extensively. In this study, we compared the soil carbon stocks of different land use types in Beijing Municipality. We collected 490 top-soil samples (top $20 \mathrm{~cm}$ ) from urban and suburban sites within the Sixth Ring Road of Beijing, which cover approximately $2400 \mathrm{~km}^{2}$, and the densities of soil organic carbon (SOC), soil inorganic carbon (SIC), and total carbon (TC) were analyzed to determine the spatial distribution of urban and suburban soil carbon characteristics across seven land use types. The results revealed significant differences in soil carbon densities among land use types. Additionally, urban soil had significantly higher SOC and SIC densities than suburban soil did, and suburban shelterbelts and productive plantations had lower SIC densities than the other land use types. The comparison of coefficients of variance (CVs) showed that carbon content of urban topsoil had a lower variability than that of suburban topsoil. Further findings revealed that soil carbon storage increased with built-up age. Urban soil built up for more than 20 years had higher densities of SOC, SIC and TC than both urban soil with less than 10 years and suburban soil. Correlation analyses indicated the existence of a significantly negative correlation between the SOC, SIC, and TC densities of urban soil and the distance to the urban core, and the distance variable alone explained $23.3 \%$ of the variation of SIC density and $13.8 \%$ of the variation of TC density. These results indicate that SOC and SIC accumulate in the urban topsoil under green space as a result of the conversion of agricultural land to urban land due to the urbanization in Beijing.
\end{abstract}

Keywords: urban soil; soil organic carbon (SOC); soil inorganic carbon (SIC); carbon stock; land use change; built-up age; Beijing; China

Citation: Luo Shanghua, Mao Qizheng, MA Keming, 2014. Comparison on soil carbon stocks between urban and suburban topsoil in Beijing, China. Chinese Geographical Science, 24(5): 551-561. doi: 10.1007/s11769-014-0709-y

\section{Introduction}

Although urban settlements cover less than $1 \%$ of the earth's surface, more than $50 \%$ of the world's population lives in cities and towns (Schneider et al., 2010), with the majority of future population growth predicted to be in these urban areas. The latest projection by the United Nations predicts that the proportion of urban population relative to total population will rise to nearly $70 \%$ worldwide by 2050 , and that $86 \%$ of this growth will be in developing regions in Asia and Africa (United Nations, 2012). Urban land coverage around the world is expanding, on average, twice as quickly as their populations are (Angel et al., 2011; Seto et al., 2011). By 2030, urban land areas will have increased by $1.2 \times 10^{6}$ $\mathrm{km}^{2}$, which would nearly triple the extent of global urban land area since 2000 (Seto et al., 2012). The impact of urban area increase on the global environment will

Received date: 2013-03-19; accepted date: 2013-07-15

Foundation item: Under the auspices of National Key Technology Research and Development Program (No. 2007BAC28B01), Innovation Project of State Key Laboratory of Urban and Regional Ecology of China

Corresponding author: MA Keming. E-mail: mkm@rcees.ac.cn

(C) Science Press, Northeast Institute of Geography and Agroecology, CAS and Springer-Verlag Berlin Heidelberg 2014 
become even more pronounced in the future (Grimm et al., 2008; Seto and Shepherd, 2009; Pickett et al., 2011; Seto et al., 2012).

Soil carbon stock, including soil organic carbon (SOC) and soil inorganic carbon (SIC) stock, is the largest carbon pool in the terrestrial ecosystem. How land use and management changes affect soil carbon storage is an important focus in global climate change research (Houghton, 1995; Lal, 2004). However, the effects of urbanization on soil remain poorly characterized (Lehmann and Stahr, 2007; Pickett and Cadenasso, 2009). A central principle in urban ecological theory implies that in urbanized landscapes anthropogenic drivers will dominate natural drivers in the control of soil carbon storage (Kaye et al., 2006). Urban land use changes entail a complex array of ecosystem alterations that are often missing from local, regional, and global estimates of soil carbon stocks (Svirejeva-Hopkins et al., 2004; Pataki et al., 2006; Pouyat et al., 2006). Therefore, the expansion of urban areas worldwide makes our understanding of the effects of urbanization on soil carbon storage increasingly important (Seto et $a l ., 2012)$. There is increasing evidence that urban ecosystems may be able to store considerable amounts of organic carbon in their vegetation and soils, but little is known about soil inorganic carbon (Nowak and Crane, 2002; Golubiewski, 2006; Lorenz et al., 2006; Pouyat et al., 2006; Churkina et al., 2010; Hutyra et al., 2011). Urban land use areas have been shown to contain larger organic carbon pools than some native deserts, grasslands, and agricultural and forested areas (Kaye et al., 2005; Pouyat et al., 2009; Koerner and Klopatek, 2010; Raciti et al., 2011). Previous research has observed the increase in inorganic carbon storage in urban soil (Koerner and Klopatek, 2010).

The majority of previous research has been focused on a limited number of samples in the United States, where historical land use and climatic factors are likely to result in differences in soil carbon storage compared to other regions. The study on urban soil carbon stocks in developing regions, where urban expansion takes place on prime agricultural land and at higher speeds, is somewhat sparse.

China, with the largest urban population and the highest rate of urban land expansion in the world, has undergone intense land use changes since the 1980s (Liu et al., 2005; Chen, 2007; Seto et al., 2011). The urbani- zation rate in China increased from $17.9 \%$ in 1978 to $51.3 \%$ in 2011, double the world average (United Nations, 2012). Total urban area in the nation has increased by 2.31 times over the past two decades, with more than half of this area converted from arable land (Liu et al., 2005; Wang et al., 2012a).

In this paper, we assessed the impact of rapid urbanization on soil carbon stocks through comparing the soil organic and inorganic carbon densities of top soils from different land use types in urban and suburban sites in Beijing, the largest city in the northern China. In this study, we aim to 1) reveal the variability of soil organic and inorganic carbon stocks in Beijing; 2) assess the effects of different land uses on soil carbon stocks; and 3 ) assess the impact of land use changes on soil carbon.

\section{Materials and Methods}

\subsection{Study area}

Beijing is a historical city located on the northern tip of the roughly triangular North China Plain $\left(39^{\circ} 28^{\prime}-\right.$ $41^{\circ} 25^{\prime} \mathrm{N}, 115^{\circ} 25^{\prime}-117^{\circ} 30^{\prime} \mathrm{E}$ ) (Fig. 1). The city has undergone rapid and sprawling urbanization over the past three decades, with urban land cover and population increasing markedly during this time period. By 2011, Beijing had a population of $2.1 \times 10^{7}$, of which $86.2 \%$ were urban residents. The urban land area has expanded from $232 \mathrm{~km}^{2}$ in 1978 to over $1200 \mathrm{~km}^{2}$ in 2005 , with nearly $50 \%$ of the increase being converted from arable land (Mu et al., 2007). The urban area of Beijing is situated in the south-central part of the city and spreads out through several concentric ring roads, of which the Sixth Ring Road passes through several satellite towns.

The city has a monsoon climate, characterized by hot, humid summer due to the East Asian monsoon, and generally cold, windy, dry winter due to the vast Siberian anticyclone. Its average annual temperature is approximately $11.5^{\circ} \mathrm{C}$ and annual precipitation exceeds $600 \mathrm{~mm}$ (more than $70 \%$ of precipitation falls from June to August). The dominant soils in the studied area are fluvo-aquic soils developed from deposited alluvium, which are classified as Fluvents of Entisols in the United States Department of Agriculture (USDA) soil taxonomic system.

\subsection{Field sampling}

The sampling of soils was conducted between July and 
August of 2009. The sampling region was centered on the Beijing urban center (Tian'anmen Square) and extends to the Sixth Ring Road, encompassing a total of $2400 \mathrm{~km}^{2}$. We used a dual gradient, spatially stratified sampling design with 128 sampling sites (Fig. 1). Sampling sites were established using a square grid of roughly $6 \mathrm{~km} \times 6 \mathrm{~km}$, situating sampling sites at the center of the grid. Additional sampling sites were situated at $3-\mathrm{km}$ intervals along the east-west, southeast-northwest, south-north and southwest-northeast transects. Within $500 \mathrm{~m}$ radius from each site, one to five $20 \mathrm{~m} \times 20 \mathrm{~m}$ plots of different land uses were randomly designated. Soil cores $(3.3 \mathrm{~cm}$ in diameter) were collected from three locations within each $20 \mathrm{~m} \times 20 \mathrm{~m}$ plot. The top $20-\mathrm{cm}$ sections of the three replicate soil cores from each plot were mixed to give a single sample per plot. In total, we obtained 490 soil samples. Three additional soil samples were collected from each plot with a $100-\mathrm{cm}^{3}$-cylindrical core for the analyses of bulk density and soil water content.

All sites were divided into groups based on urbanization level (urban or suburban) and the land use types. Urban sites included built-up areas inside Fifth Road Ring and its surroundings, while suburban sites consisted of areas with minimal development between the Fifth Ring Road and Sixth Ring Road. The seven land-use categories were institutional $(n=56$. urban 32, suburban 24), residential ( $n=76$. urban 60, suburban $16)$, park $(n=49$. urban 27 , suburban 22$)$, transportation (roadside green space, $n=123$. urban 64, suburban 59), roadside pit ( $n=104$. urban 55, suburban 49$)$, shelterbelt (green buffer, $n=55$. suburban 55), and productive plantation (nurseries/orchards, $n=27$. suburban 27). The land use types are in according with Chinese standards for the classification of urban green space (CJJ-/-T-85-2002).

\subsection{Laboratory analysis}

Soil samples were air-dried and sieved to analyze the chemical properties $(<1 \mathrm{~mm}$ for $\mathrm{pH}$ determination and $<$ $0.21 \mathrm{~mm}$ for total carbon (TC) and total nitrogen (TN) determination). Using a Delta $320 \mathrm{pH}$ meter (Mettler-Toledo Instruments (Shanghai) Ltd., China), soil $\mathrm{pH}$ was determined in distilled water at a soil-to-solution ratio of $1: 2.5$ (by volume). The TC and TN concentrations were obtained by combustion using an elemental analyzer (Elementar, Hanau, Germany). The SOC was analyzed using the potassium-dichromate oxidation method, with a correction factor of 1.1 used to estimate $100 \%$ organic carbon recovery. Lastly, SIC content was calculated by subtracting SOC from TC.

Soil samples destined for soil water content and bulk density estimations were dried at $105^{\circ} \mathrm{C}$ to a constant mass and weighed to determine the soil bulk densities and soil water contents by dry weight. For all data, the density of carbon in a unit area $\left(1 \mathrm{~m}^{2}\right)$ was calculated as follows:

$C_{\mathrm{d}}=C_{\mathrm{f}} B_{\mathrm{d}} D\left(1-\delta_{2 \mathrm{~mm}}\right) / 100$
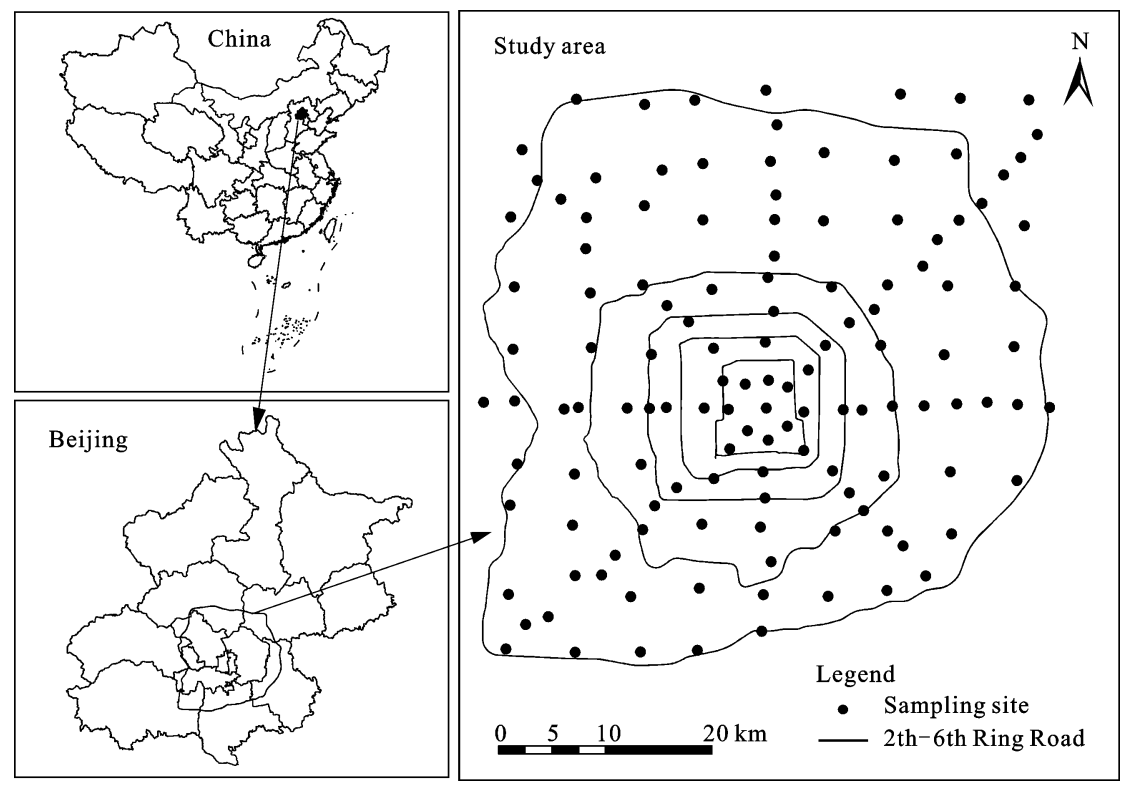

Fig. 1 Location of study area and sampling sites 
where $C_{\mathrm{d}}$ is carbon density; $C_{\mathrm{f}}$ is content of SOC; $B_{\mathrm{d}}$ is bulk density; $D$ is thickness (here, $20 \mathrm{~cm}$ ); and $\delta_{2 \mathrm{~mm}}$ is the fraction of material larger $>2 \mathrm{~mm}$ in the layer.

\subsection{Statistical analysis}

We used the Kruskal-Wallis test (a non-parametrical analogous test) followed by the Nemenyi test to examine the differences in soil carbon stocks between land use types. Correlation and regression analyses were used to test the relationships between soil carbon and distance to the urban center. Statistical significance was determined to be $p \leq 0.05$, unless otherwise noted. All statistical analyses were performed using PASW Statistics version 18.0.

\section{Results}

\subsection{Soil properties}

Large variations were observed within urban land, suburban land, and throughout the study area as a whole for SOC, SIC, TC, and TN (Table 1). The coefficients of variance $(\mathrm{CVs})$ of soil carbon concentrations ranged from $41.3 \%$ for urban TC density to $64.6 \%$ for suburban SIC density. The CVs of soil carbon density ranged from $37.1 \%$ for urban TC density to $68.0 \%$ for suburban SIC density. The CVs of the ratio of TOC/TN and of SOC/TC ranged from $23.6 \%$ to $34.8 \%$. In contrast, soil $\mathrm{pH}$ and bulk density had relatively low CVs of less than $10 \%$.
The comparisons of soil properties between urban and suburban soils revealed significant differences, except for soil TN. The concentrations and densities of urban soil carbon were higher than those of suburban soils carbon. Urban soil carbon concentrations were $14 \%, 40 \%$, and $25 \%$ higher for SOC, SIC, and TC respectively than suburban soil. Urban soil had 16\%, 41\% and $27 \%$ higher SOC, SIC and TC densities respectively than suburban soil. The percentages of SOC in urban soil were lower than those in suburban soil. Urban soil $\mathrm{pH}$, bulk densities, and TN concentrations were slightly higher than those of suburban soil, and did not differ statistically.

\subsection{Effect of land use}

There were statistically significant differences in soil carbon density among different land use types (Fig. 2). For the urban sites, roadside pits had the highest SOC, SIC, and TC densities, while parks had the lowest. The differences in SOC between different urban land use types were not significant. For the suburban sites, roadside pits also had the highest SOC, SIC and TC densities. Similar to urban sites, the differences in SOC and $\mathrm{TC}$ between other land use types were not significant for suburban sites. However, shelterbelts and productive plantations had lower SIC densities than other land use types throughout the study area. Productive plantations, shelterbelts, and parks also had higher percentages of SOC.

Table 1 Descriptive statistics of soil properties sampled from urban and suburban sites in study area

\begin{tabular}{|c|c|c|c|c|c|c|c|c|c|c|}
\hline & \multicolumn{4}{|c|}{ Urban $(n=233)$} & \multicolumn{4}{|c|}{ Suburban $(n=257)$} & \multicolumn{2}{|c|}{ Regional $(n=490)$} \\
\hline & Min & Max & Mean (SE) & $\mathrm{CV}$ & Min & Max & Mean (SE) & $\mathrm{CV}$ & Mean (SE) & $\mathrm{CV}$ \\
\hline $\mathrm{SOC}(\mathrm{g} / \mathrm{kg})$ & 2.43 & 64.28 & $11.22(0.38)^{\mathrm{a}}$ & 52.2 & 1.68 & 51.73 & $9.80(0.32)^{b}$ & 52.7 & $10.48(0.25)$ & 52.9 \\
\hline $\mathrm{SIC}(\mathrm{g} / \mathrm{kg})$ & 0.83 & 25.94 & $9.82(0.31)^{\mathrm{a}}$ & 47.5 & 0.19 & 22.73 & $7.00(0.28)^{b}$ & 64.6 & $8.33(0.22)$ & 57.5 \\
\hline $\mathrm{TC}(\mathrm{g} / \mathrm{kg})$ & 8.54 & 85.82 & $21.04(0.57)^{\mathrm{a}}$ & 41.3 & 3.80 & 65.37 & $16.80(0.48)^{\mathrm{b}}$ & 45.8 & $18.81(0.38)$ & 44.9 \\
\hline $\operatorname{SOCd}\left(\mathrm{kg} / \mathrm{m}^{2}\right)$ & 0.67 & 13.08 & $3.07(0.09)^{\mathrm{a}}$ & 45.7 & 0.48 & 15.48 & $2.63(0.09)^{\mathrm{b}}$ & 54.0 & $2.83(0.06)$ & 50.3 \\
\hline $\operatorname{SICd}\left(\mathrm{kg} / \mathrm{m}^{2}\right)$ & 0.23 & 7.33 & $2.70(0.08)^{\mathrm{a}}$ & 46.7 & 0.05 & 6.91 & $1.91(0.08)^{b}$ & 68.0 & $2.28(0.06)$ & 58.6 \\
\hline $\operatorname{TCd}\left(\mathrm{kg} / \mathrm{m}^{2}\right)$ & 2.37 & 17.46 & $5.77(0.14)^{\mathrm{a}}$ & 37.1 & 1.12 & 19.56 & $4.54(0.14)^{b}$ & 48.0 & $5.12(0.10)$ & 43.8 \\
\hline SOC/TC $(\%)$ & 19.96 & 92.53 & $53.70(0.97)^{\mathrm{b}}$ & 27.5 & 15.77 & 97.99 & $59.91(1.08)^{\mathrm{a}}$ & 29.1 & $56.97(0.74)$ & 28.9 \\
\hline $\mathrm{TN}(\mathrm{g} / \mathrm{kg})$ & 0.30 & 2.46 & $0.91(0.02)^{\mathrm{a}}$ & 35.4 & 0.23 & 2.25 & $0.88(0.02)^{\mathrm{a}}$ & 33.9 & $0.89(0.01)$ & 34.6 \\
\hline $\mathrm{TOC} / \mathrm{TN}$ & 4.47 & 26.10 & $12.18(0.19)^{\mathrm{a}}$ & 23.6 & 4.09 & 42.59 & $10.97(0.24)^{b}$ & 34.8 & $11.54(0.16)$ & 29.9 \\
\hline $\mathrm{pH}$ & 7.43 & 8.77 & $8.06(0.01)^{\mathrm{a}}$ & 2.2 & 7.43 & 8.59 & $8.03(0.01)^{\mathrm{b}}$ & 2.5 & $8.04(0.01)$ & 2.4 \\
\hline Bulk density $\left(\mathrm{g} / \mathrm{cm}^{3}\right)$ & 1.02 & 1.66 & $1.39(0.01)^{\mathrm{a}}$ & 7.7 & 0.96 & 1.67 & $1.35(0.01)^{\mathrm{b}}$ & 10.3 & $1.37(0.01)$ & 9.2 \\
\hline
\end{tabular}

Notes: SOC, soil organic carbon; SIC, soil inorganic carbon; TC, total carbon; TN, total soil nitrogen; TOC: total organic carbon; SOCd: soil organic carbon density; SICd: soil inorganic carbon density; TCd: total carbon density. Means with different letters were significantly different, and comparisons were done with analysis of variance 

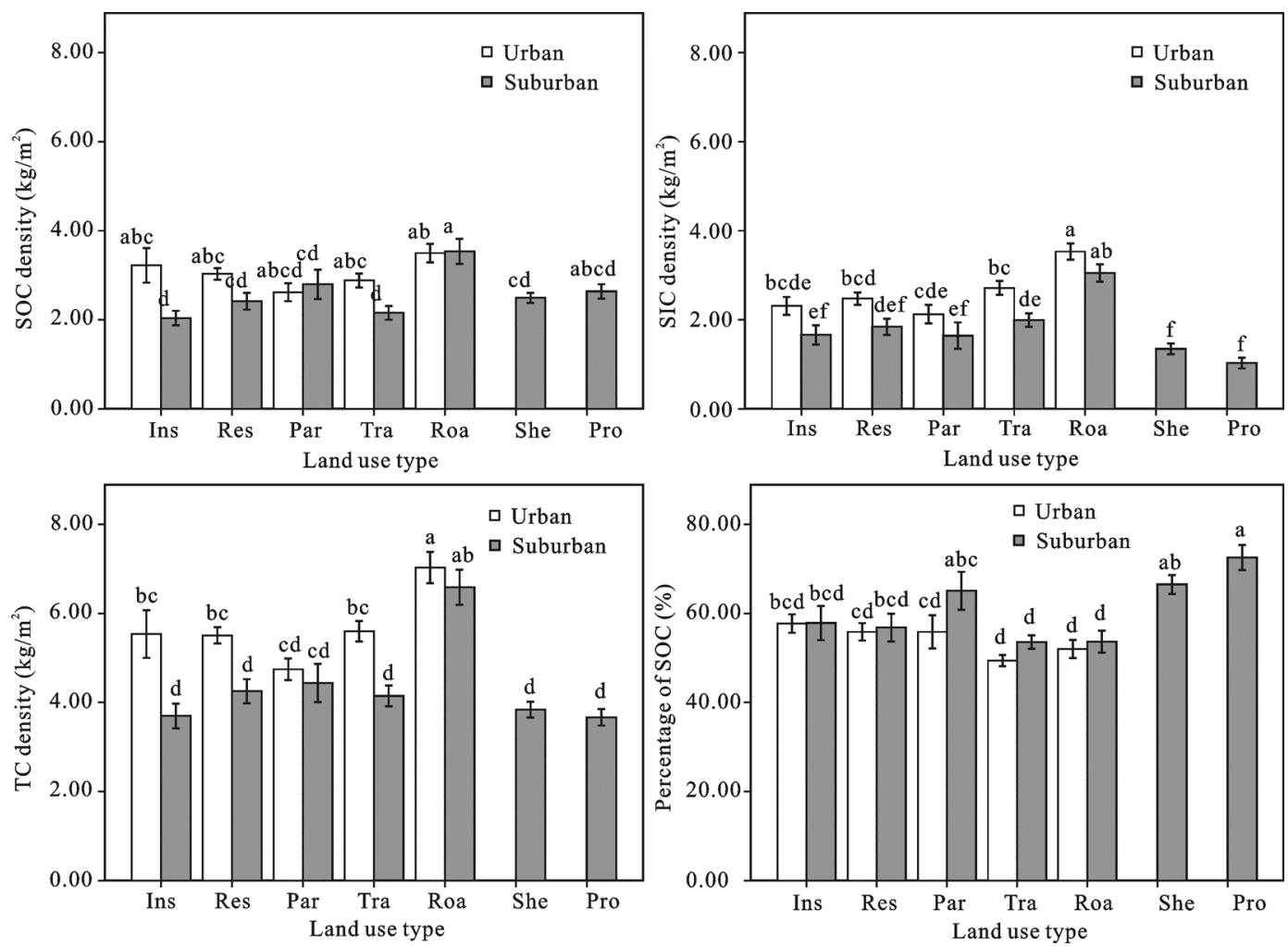

Fig. 2 Mean ( \pm SE) soil carbon densities (0-20 cm depths) of land use types in study area. Ins, institutional; Res, residential; Par, park; Tra, transportation; Roa, roadside pit; She, shelterbelt; Pro, productive plantation. SOC, soil organic carbon; SIC, soil inorganic carbon; $\mathrm{TC}$, total soil carbon. Comparisons were done with a Kruskal-Wallis test. Means with different letters were significantly different

Comparing urban and suburban sites of the same land use type, urban institutional and transportation sites had significantly higher SOC densities than the same types located in suburban sites. On the other hand, SOC densities in parks and roadside pits were slightly higher in suburban samples. The SIC densities in transportation and TC densities in residential, transportation, and institutional sites were higher for urban land use types when compared to those of the same land use types located in suburban sites.

\subsection{Effect of built-up age}

There were notable differences in soil carbon densities between urban sites of varying built-up ages (Fig. 3). Urban soil with at least 20 years of buildup had higher SOC, SIC, and TC densities than urban soil with less than 10 years of buildup. The same trend was observed when comparing soil carbon densities between urban soil with at least 20 years of buildup and suburban soils. Urban soil with buildup dating back to the 1980 s had $37 \%, 41 \%$, and $39 \%$ more SOC, SIC, and TC, respectively, than urban soil with buildup dating back to the 2000s. Likewise, urban soil with buildup from the 1980 s had $34 \%, 68 \%$, and $47 \%$ more SOC, SIC, and TC, respectively, than suburban soil. However, soil with buildup prior to 1980 had slightly lower carbon density than urban soil with buildup during the 1980s, but the

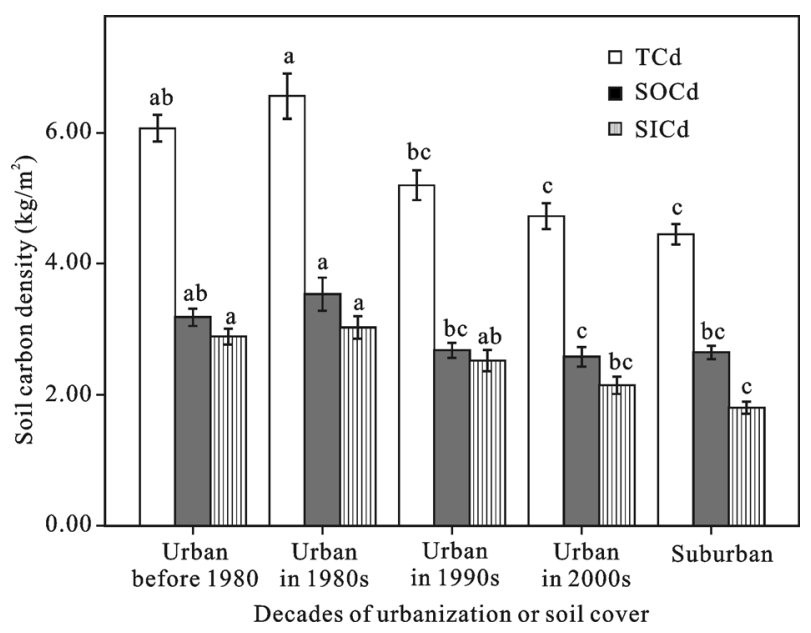

Fig. 3 Mean $( \pm \mathrm{SE})$ soil carbon densities (0-20 cm depths) of urban soil with different built-up ages and suburban soil in study area. SOCd, soil organic carbon density; SICd, soil inorganic carbon density; $\mathrm{TCd}$, total carbon density. Comparisons were done with a Kruskal-Wallis test. Means with different letters were significantly different 
differences were not significant.

\subsection{Effect of distance to urban center}

Significant relationships $(p<0.01)$ were found when comparing SOC, SIC, and TC densities with respect to distance from the urban center. Spearman correlation coefficients were $-0.233,-0.538$, and -0.500 , respectively. Regressions of SOC, SIC and TC densities against distance to the urban center were also statistically significant. Distance from the urban center explained $23.3 \%$ and $13.8 \%$ variations of SIC and TC (Fig. 4), respectively, among plots, while the determination coefficient $\left(R^{2}\right)$ of SOC was too low. These results suggested a general trend that SOC, SIC, and TC decreased as a function of distance from the urban center in the study area.

\section{Discussion}

\subsection{Variability of soil carbon stock}

Our results indicate that the soil carbon stock in the topsoil in the study area varied considerably. The coefficients of variation of SOC and SIC are both more than $50 \%$ (52.9\% and 57.5\%, respectively), which are much higher than those of soil $\mathrm{pH}$ and bulk density. These results support the previous findings of Pouyat et al. (2007) that urban soil chemical properties (with the exception of soil $\mathrm{pH}$ ) generally varied more than physical properties did. In another study, they found that variations in SOC density were higher within a city than among cities for a given soil type (Pouyat et al., 2002). The maximum compared to the minimum of SOC and SIC densities in the study area is over 10 -fold, which is consistent with previous studies in the United States and Germany (Pouyat et al., 2002; Pouyat et al., 2007; Lorenz and Lal, 2009). The results of these studies suggested that soil carbon stocks varied widely in urban landscapes, which can be described as 'urban soil mosaic' (Pouyat et al., 2006; Pouyat et al., 2007).

In comparison to the US cities, the mean SOC density $\left(2.83 \mathrm{~kg} / \mathrm{m}^{2}\right)$ of the study area is lower than that of many cities in the US, such as Baltimore and Denver (more than $\left.4.0 \mathrm{~kg} / \mathrm{m}^{2}\right)$, and Fort Collins $\left(6.942 \mathrm{~kg} / \mathrm{m}^{2}\right.$, to $30 \mathrm{~cm}$ depth), but higher than that of Phoenix (less than $2 \mathrm{~kg} / \mathrm{m}^{2}$, to $30 \mathrm{~cm}$ depth) (Kaye et al., 2008). However, the mean SIC density of the study area $\left(2.28 \mathrm{~kg} / \mathrm{m}^{2}\right)$ is much higher than that of Phoenix $\left(0.39 \mathrm{~kg} / \mathrm{m}^{2}\right)$ and Fort Collins $\left(0.325 \mathrm{~kg} / \mathrm{m}^{2}\right.$, to $30 \mathrm{~cm}$ depth) (Kaye et al., 2005; Kaye et al., 2008; Pouyat et al., 2009). We suspect that the relatively low SOC densities in the study area are due to the lower SOC densities of native soils, while higher SIC densities are due to carbonate materials incorporated during green-space construction (Lehmann and Stahr, 2007; Yu et al., 2007).

Another city within China that has experienced rapid and expansive development similar to Beijing is Shanghai, with a population of $2.3 \times 10^{7}$ persons. The comparison results of soil carbon density for the two cities reveal that the range and CVs of soil carbon density in Beijing were higher than those in Shanghai. The mean SOC densities of urban and suburban soil in Shanghai $\left(3.93 \mathrm{~kg} / \mathrm{m}^{2}\right.$ and $3.74 \mathrm{~kg} / \mathrm{m}^{2}$, respectively) are higher than those in Beijing $\left(3.07 \mathrm{~kg} / \mathrm{m}^{2}\right.$ and $2.63 \mathrm{~kg} / \mathrm{m}^{2}$, respectively), and the SIC densities of Shanghai $\left(1.12 \mathrm{~kg} / \mathrm{m}^{2}\right.$ and $0.73 \mathrm{~kg} / \mathrm{m}^{2}$, respectively) are lower than those of Beijing $\left(2.07 \mathrm{~kg} / \mathrm{m}^{2}\right.$ and $1.91 \mathrm{~kg} / \mathrm{m}^{2}$, respectively)

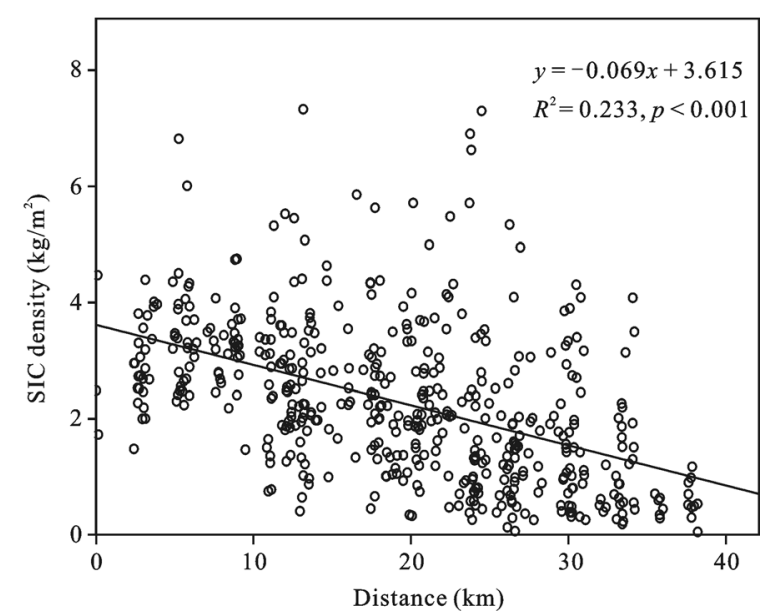

Fig. 4 Plot of total carbon (TC) and soil inorganic carbon (SIC) densities as a function of distance to urban center 
(Xu et al., 2012), in accordance with the trend observed between Beijing and US cities. However, the results of previous studies on Shanghai showed that the mean SOC concentration in urban areas $(11.21 \mathrm{~g} / \mathrm{kg})$ is very close to that of Beijing (11.22 g/kg) (Hao et al., 2011), and that Beijing and Shanghai have similar lower SOC density backgrounds ( $\mathrm{Yu}$ et al., 2007). These findings support the urban convergence hypothesis proposed by Pouyat et al. (2009) that urban land use change drives ecosystem structure and function (e.g., SOC density) toward a range of similar endpoints, and that anthropogenic drivers will dominate natural drivers in the control of SOC storage.

\subsection{Effect of land use on soil carbon stock}

Land use can serve as an indicator of disturbance, site history, and management; these factors have the potential to affect soil characteristics (Pouyat et al., 2010). The results of this study demonstrated that land use has an important impact on soil carbon, as there were significant differences in SOC, SIC and TC densities among different land use types throughout the study area. In contrast, there were no significant differences in SOC, SIC, and TC densities among land use types within urban areas, with the exception of the roadside pits which had higher soil carbon density (Fig. 2). A similar pattern was found in the Chongwen District of Beijing where there were no differences between the soil organic matter (SOM) of urban parks, residential lands, and transport lands, although roadside pits had lower SOM (Liu et al., 2010). This can be explained by the differences in sampling intensities, as fewer samples were collected within an area of $16.46 \mathrm{~km}^{2}$ (Liu et al., 2010) relative to the much more expansive sampling plan in this study.

The results of our study showed that urban soil had a greater range of SOC and SIC concentration and density than suburban soil, but that the CVs of SOC, SIC, and TC of urban soil were lower than those of suburban soil. The suburban shelterbelt and productive plantation soils converted from agricultural soils had much lower SIC densities than those of the other land use types. These can be partially explained by anthropogenic organic or inorganic particles incorporated in soils during greenspace construction, such as technogenic substrates like rubble, bricks, slags, ashes, waste, and sludge (Lehmann and Stahr, 2007; Xia et al., 2011; Nehls et al., 2012;
Wang et al., 2012b). This also supports the hypothesis that the impact of human-caused disturbance (e.g., movements of soil and building construction) is more pronounced during, rather than after, the landdevelopment process (Kaye et al., 2006).

\subsection{Effect of urbanization on soil carbon stock}

Urban areas have the potential to either sequester or lose SOC. In a comparison of carbon stocks in urban and native soils around six US cities, Pouyat et al. (2006) found that in the northeastern cities, urban SOC densities were lower than those of natural or agricultural soils, but were higher than those of pre-urban development soils in warmer or more arid regions. Conversely, our observations revealed that urban soils contain higher SOC and SIC densities than suburban soils in the study area (Table 1) and that urban soils accumulate carbon with increasing time (Fig. 3) and decreasing distance to the urban center (Fig. 4).

We found that the SOC, SIC, and TC densities of urban soils were 1.17 times, 1.41 times, and 1.27 times higher, respectively, than those of suburban soils. Compared to the results of other agricultural soil investigations, our findings are consistent with others with respect to higher SOC concentrations and densities in metropolitan areas than those of rural and agricultural soils in Beijing. For example, the mean SOC concentrations of urban soil and suburban soil $(11.22 \mathrm{~g} / \mathrm{kg}$ and 9.8 $\mathrm{g} / \mathrm{kg}$, respectively) were higher than those of arable soil in the Daxing District $(7.44 \mathrm{~g} / \mathrm{kg})(\mathrm{Hu}$ et al., 2007) and arable soil in the Pinggu District of Beijing $(8.38 \mathrm{~g} / \mathrm{kg})$ (Wang et al., 2008). Additionally, the mean SOC density $\left(2.83 \mathrm{~kg} / \mathrm{m}^{2}\right)$ was higher than the SOC density of agricultural land in the Yanqing County, Beijing (from $2.47 \mathrm{~kg} / \mathrm{m}^{2}$ to $2.74 \mathrm{~kg} / \mathrm{m}^{2}$ at $0-25 \mathrm{~cm}$ depth) (Zhang et al., 2006). In Shenyang City, urban green-space soil had 1.23-1.44 times more SOC content than rural agricultural land (Duan et al., 2008); likewise, the mean urban topsoil SOC density in Kaifeng City was 2.53 times higher than that of the suburbs (Sun et al., 2010). Urban surface SOC densities in Shanghai were 1.05 times and 1.26 times higher than those of suburban and rural areas (Xu et al., 2012).

Previous studies outside China have confirmed higher SOC concentrations and densities in urban areas. Similar results were also found in the Colorado Front Range (Golubiewski, 2006) and Phoenix, both in the U.S. 
(Kaye et al., 2008), and Leicester, UK (Edmondson et al., 2012). Therefore, the influence of urbanization on soil carbon may be particularly great in former agricultural areas, which are often depleted in carbon at the time of development, but may accumulate carbon over time (Compton and Boone, 2000; Knops and Tilman, 2000; Post and Kwon, 2000; Pouyat et al., 2009). These results may be explained by both direct and indirect effects of urbanization on urban soils. Direct effects include physical disturbances, burial, coverage of soil by fill material and impervious surfaces, and soil management inputs (e.g., fertilization and irrigation). Indirect effects involve the changes in the abiotic and biotic environments as areas that can influence soil development in intact soils are urbanized (Zhang et al., 2003; Kaye et al., 2006; Pouyat et al., 2006).

Comparisons of soil carbon storages between the different age subdivisions suggest that urban land use change can increase SOC and SIC densities with time in Beijing (Fig. 3). The results indicate that older urban soil disturbed by development accumulates more carbon than younger soil. This result is consistent with chronosequence studies in Beijing and other locations. $\mathrm{Hu}$ et al. (2007) and Kong et al. (2009) found that the SOM levels in the urban-rural transition zone in Beijing slightly increased from low to high levels during 1980-2000. In the Denver-Boulder metropolitan area in the U.S., urban SOC concentration decreased below native grassland concentration in the first decade after construction, but then rose and surpassed the SOC concentration of grasslands within two decades of development (Golubiewski, 2006). Results from chronosequence sites in Baltimore, U.S., suggest that former agricultural areas have the potential to accumulate carbon rapidly over the 40 years following residential development (Raciti et al., 2011). A study on golf courses near metropolitan Denver and Fort Collins, U.S., showed sharp increase in soil carbon over the first 25-30 years after development and that maximum SOC accumulation in turf grass systems occurred between 30 and 50 years following development (Qian and Follett, 2002). The results of a study on Hangzhou, China also showed that urban turf SOC accumulation continued for over 40 years following development (Liu and Zhang, 2010). The results in Beijing indicating that the SOC density of $>30$-year-old urban soil is slightly lower than that of $>20$-year-old urban soil suggest that accumula- tion of carbon in $>30$-year-soil is still uncertain in this region. The reason is that due to the Beijing 2008 Summer Olympics, a lot of new green-space construction took place and existing green space underwent a large-scale renovation and reconstruction in the old town area of Beijing, which had been urbanized for over 30 years. The topsoil carbon stocks were drastically disturbed during reconstruction.

The results of our study also revealed that soil carbon stock decreased with distance from the urban center. The same was true for SOC, SIC, and TC. This trend is consistent with a urban-rural gradient transect study in New York, U.S. (Pouyat et al., 2002), which showed that urban environments can affect soil properties in remnant forest patches along urban-rural environmental gradients. In New York, distance from the urban core accounted for approximately $23 \%$ of the variations in SOM among plots, but organic carbon density and concentration were not statistically significant when regressed against distance. In this study, the distance from the urban center explained $23.3 \%$ and $13.8 \%$ of the respective variations in SIC and TC densities among plots, but the SOC densities were not statistically significant. This discrepancy can be explained by the effects of anthropogenic drivers (management and disturbance) coupled with environmental factors that result in more complex soil carbon dynamics.

The urban built-up area in Beijing was increased by over $1000 \mathrm{~km}^{2}$ from 1973 to 2005 , of which approximately $54 \%$ was converted from constructed land and approximately $43 \%$ was converted from arable land in the suburban area (Mu et al., 2007). Now, over $42 \%$ of the built-up areas in Beijing are covered by green space. The results of this study found that the carbon densities of urban topsoil under green space were higher than those of suburban green space and rural arable land. This indicates that agricultural land converted to urban green space in Beijing has the strong potential to accumulate soil organic carbon and soil inorganic carbon.

Due to the difficulty of sampling, this study only involved surface soil (top $20 \mathrm{~cm}$ ) in open, urban space, and did not involve soil carbon stock in subsurface soil or soil beneath impervious surfaces, which cover a substantial proportion of urban land. We suggest that more data are needed on highly disturbed soils, and that an understanding of the carbon characteristics of soil at higher depths and soil beneath impervious surfaces is 
needed to fully address the changes occurring in soil carbon stocks due to urban land-use conversion. The drivers of soil carbon accumulation in metropolitan areas need further study.

\section{Conclusions}

The comparison of soil carbon storage in the vegetated spaces of urban areas with that of suburban areas reveals a certain increase in carbon storage. This study reveals that the topsoil carbon densities in the metropolitan area of Beijing have a high spatial variability, and that SOC and SIC have a large range and coefficient of variation. The significant differences in soil carbon densities among different land use types indicate the decisive role of the human effect on the nature of urban soils. The results suggest that urban soil carbon stock accumulates with the passage of the time, and urban soil with at least 20 years of buildup has higher SOC compared to soil with less 10 years and suburban soil. The analysis of the relationship between urban carbon densities and distance from the urban center indicates that TC and SIC densities decrease significantly with the distance to the urban center. These results suggest that SOC and SIC accumulate in the urban topsoil under green space as a result of the conversion of agricultural land to urban land due to the urbanization in Beijing.

\section{Acknowledgements}

The authors thank Tang Rongli, Bao Le, and Tong Kangkang for their assistance in the field survey. We would also like to extend our thanks to James Page, Alexander Carnes and Qu Laiye, who carefully reviewed the language of this manuscript.

\section{References}

Angel S, Parent J, Civco D L et al., 2011. The dimensions of global urban expansion: Estimates and projections for all countries, 2000-2050. Progress in Planning, 75(2): 53-107. doi: 10.1016/j.progress.2011.04.001

Chen J, 2007. Rapid urbanization in China: A real challenge to soil protection and food security. Catena, 69(1): 1-15. doi: 10.1016/j.catena.2006.04.019

Churkina G, Brown D G, Keoleian G, 2010. Carbon stored in human settlements: The conterminous United States. Global Change Biology, 16(1): 135-143. doi: 10.1111/j.1365-2486. 2009.02002.x
Compton J E, Boone R D, 2000. Long-term impacts of agriculture on soil carbon and nitrogen in New England forests. Ecology, 81(8): 2314-2330. doi: 10.1890/0012-9658(2000)081 [2314:Ltioao]2.0.Co;2

Duan Yingqiu, Wei Zhongyi, Han Chunlan et al., 2008. Contents of organic carbon urban soil in different land use type areas, Northeast China. Journal of Shenyang Agricultural University, 39(3): 324-326. (in Chinese)

Edmondson J L, Davies Z G, McHugh N et al., 2012. Organic carbon hidden in urban ecosystems. Scientific Reports, 2: 963. doi: $10.1038 /$ srep00963

Golubiewski N E, 2006. Urbanization increases grassland carbon pools: Effects of landscaping in Colorado's front range. Ecological Applications, 16(2): 555-571. doi: 10.1890/1051-0761 (2006)016[0555:UIGCPE]2.0.CO;2

Grimm N B, Faeth S H, Golubiewski N E et al., 2008. Global change and the ecology of cities. Science, 319(5864): 756-760. doi: 10.1126/science. 1150195

Hao Ruijun, Fang Hailan, Shen Lieying, 2011. Distribution characteristics of soil organic carbon and total nitrogen in greenbelt soil in Shanghai center city. Journal of Nanjing Forestry University (Natural Science Edition), 35(6): 49-52. (in Chinese)

Houghton R A, 1995. Land-use change and the carbon cycle. Global Change Biology, 1(4): 275-287. doi: 10.1111/j.13652486.1995.tb00026.x

Hu K L, Li H, Li B G et al., 2007. Spatial and temporal patterns of soil organic matter in the urban-rural transition zone of Beijing. Geoderma, 141(3-4): 302-310. doi: 10.1016/j.geoderma. 2007.06.010

Hutyra L R, Yoon B, Alberti M, 2011. Terrestrial carbon stocks across a gradient of urbanization: A study of the Seattle, WA region. Global Change Biology, 17(2): 783-797. doi: 10.1111/ j.1365-2486.2010.02238.x

Kaye J P, Groffman P M, Grimm N B et al., 2006. A distinct urban biogeochemistry? Trends in Ecology \& Evolution, 21(4): 192-199. doi: 10.1016/j.tree.2005.12.006

Kaye J P, Majumdar A, Gries C et al., 2008. Hierarchical Bayesian scaling of soil properties across urban, agricultural, and desert ecosystems. Ecological Applications, 18(1): 132-145. doi: 10.1890/06-1952.1

Kaye J P, McCulley R L, Burke I C, 2005. Carbon fluxes, nitrogen cycling, and soil microbial communities in adjacent urban, native and agricultural ecosystems. Global Change Biology, 11(4): 575-587. doi: 10.1111/j1365-2486.2005.00921.x

Knops J M H, Tilman D, 2000. Dynamics of soil nitrogen and carbon accumulation for 61 years after agricultural abandonment. Ecology, 81(1): 88-98. doi: 10.1890/0012-9658(2000) 081[0088:DOSNAC]2.0.CO;2

Koerner A B, Klopatek M J, 2010. Carbon fluxes and nitrogen availability along an urban-rural gradient in a desert landscape. Urban Ecosystems, (13): 1-21. doi: 10.1007/s11252-009-0105-Z

Kong X, Dao T H, Qin J et al., 2009. Effects of soil texture and land use interactions on organic carbon in soils in North China cities' urban fringe. Geoderma, 154(1): 86-92. doi: 10.1016/ 
j.geoderma.2009.09.016

Lal R, 2004. Soil carbon sequestration impacts on global climate change and food security. Science, 304(5677): 1623-1627. doi: 10.1126/science.1097396

Lehmann A, Stahr K, 2007. Nature and significance of anthropogenic urban soils. Journal of Soils and Sediments, 7(4): 247-260. doi: 10.1065/jss2007.06.235

Liu J, Tian H, Liu M et al., 2005. China's changing landscape during the 1990s: Large-scale land transformations estimated with satellite data. Geophysical Research Letters, 32(2): L02405. doi: 10.1029/2004gl021649

Liu Yan, Wang Cheng, Peng Zhenhua et al., 2010. Soil enzyme activity and its relationship with soil phosico-chemical properties in green areas of Chongwen District of Beijing. Journal of Northeast Forestry University, 38(4): 66-70. (in Chinese)

Liu Zhaoyun, Zhang Mingkui, 2010. Effects of green space age on organic carbon accumulated in urban soils. Chinese Journal of Ecology, 29(1): 142-145. (in Chinese)

Lorenz K, Lal R, 2009. Biogeochemical C and N cycles in urban soils. Environment International, 35(1): 1-8. doi: 10.1016/ j.envint.2008.05.006

Lorenz K, Preston C M, Kandeler E, 2006. Soil organic matter in urban soils: Estimation of elemental carbon by thermal oxidation and characterization of organic matter by solid-state C-13 nuclear magnetic resonance (NMR) spectroscopy. Geoderma, 130(3-4): 312-323. doi: 10.1016/j.geoderma.2005.02.004

$\mathrm{Mu}$ Fengyun, Zhang Zengxiang, Chi Yaobin et al., 2007. Dynamic monitoring of built-up area in Beijing during 1973-2005 based on multi original remote sensed images. Journal of Remote Sensing, 11(2): 257-268. (in Chinese)

Nehls T, Rokia S, Mekiffer B et al., 2012. Contribution of bricks to urban soil properties. Journal of Soils and Sediments, 13(3): 575-584. doi: 10.1007/s11368-012-0559-0

Nowak D J, Crane D E, 2002. Carbon storage and sequestration by urban trees in the USA. Environmental Pollution, 116(3): 381-389. doi: 10.1016/S0269-7491(01)00214-7

Pataki D E, Alig R J, Fung A S et al., 2006. Urban ecosystems and the North American carbon cycle. Global Change Biology, 12(11): 2092-2102. doi: 10.1111/j.1365-2486.2006.01242.x

Pickett S T A, Cadenasso M L, Grove J M et al., 2011. Urban ecological systems: Scientific foundations and a decade of progress. Journal of Environmental Management, 92(3): 331-362. doi: 10.1016/j.jenvman.2010.08.022

Pickett S, Cadenasso M, 2009. Altered resources, disturbance, and heterogeneity: A framework for comparing urban and non-urban soils. Urban Ecosystems, 12(1): 23-44. doi: 10.1007/s11252-008-0047-x

Post W M, Kwon K C, 2000. Soil carbon sequestration and land-use change: Processes and potential. Global Change Biology, 6(3): 317-327. doi: 10.1046/j.1365-2486.2000.00308.x

Pouyat R V, Szlavecz K, Yesilonis I D et al., 2010. Chemical, physical, and biological characteristics of urban soils. Urban Ecosystem Ecology. Agronmy. Monograph, 55: 119-152. doi: 10.2134/agronmonogr55.c7
Pouyat R V, Yesilonis I D, Nowak D J, 2006. Carbon storage by urban soils in the United States. Journal of Environmental Quality, 35(4): 1566-1575. doi: 10.2134/Jeq2005.0215

Pouyat R V, Yesilonis I D, Russell-Anelli J et al., 2007. Soil chemical and physical properties that differentiate urban land-use and cover types. Soil Science Society of America Journal, 71(3): 1010-1019. doi: 10.2136/sssaj2006.0164

Pouyat R, Groffman P, Yesilonis I et al., 2002. Soil carbon pools and fluxes in urban ecosystems. Environmental Pollution, 116 (Supp. 1): S107-S118. doi: 10.1016/S0269-7491(01) 00263-9

Pouyat R, Yesilonis I, Golubiewski N, 2009. A comparison of soil organic carbon stocks between residential turf grass and native soil. Urban Ecosystems, 12(1): 45-62. doi: 10.1007/s11252008-0059-6

Qian Y L, Follett R F, 2002. Assessing soil carbon sequestration in turfgrass systems using long-term soil testing data. Agronomy Journal, 94(4): 930-935. doi: 10.2134/agronj2002.9300

Raciti S M, Groffman P M, Jenkins J C et al., 2011. Accumulation of carbon and nitrogen in residential soils with different land-use histories. Ecosystems, 14(2): 287-297. doi: 10.1007/s 10021-010-9409-3

Schneider A, Friedl M A, Potere D, 2010. Mapping global urban areas using MODIS 500-m data: New methods and datasets based on 'urban ecoregions'. Remote Sensing of Environment, 114(8): 1733-1746. doi: 10.1016/j.rse.2010.03.003

Seto K C, Fragkias M, Güneralp B et al., 2011. A meta-analysis of global urban land expansion. PLOS ONE, 6(8): e23777. doi: 10.1371/journal.pone.0023777

Seto K C, Güneralp B, Hutyra L R, 2012. Global forecasts of urban expansion to 2030 and direct impacts on biodiversity and carbon pools. Proceedings of the National Academy of Sciences, 109(40): 16083-16088. doi: 10.1073/pnas.1211658109

Seto K C, Shepherd J M, 2009. Global urban land-use trends and climate impacts. Current Opinion in Environmental Sustainability, 1(1): 89-95. doi: 10.1016/j.cosust.2009.07.012

Sun Y L, Ma J H, Li C, 2010. Content and densities of soil organic carbon in urban soil in different function districts of Kaifeng. Journal of Geographical Sciences, 20(1): 148-156. doi: 10.1007/s11442-010-0148-3

Svirejeva-Hopkins A, Schellnhuber H J, Pomaz V L, 2004. Urbanized territories as a specific component of the global carbon cycle. Ecological Modelling, 173(2-3): 295-312. doi: 10.1016/j.ecolmodel.2003.09.022

United Nations, 2012. World Urbanization Prospects: The 2011 Revision. New York: United Nations Department of Economic and Social Affairs.

Wang Lei, Li Congcong, Ying Qing et al., 2012a. China's urban expansion from 1990 to 2010 determined with satellite remote sensing. Chinese Science Bulletin, 57(16): 1388-1399. (in Chinese)

Wang M, Markert B, Chen W et al., 2012b. Identification of heavy metal pollutants using multivariate analysis and effects of land uses on their accumulation in urban soils in Beijing, China. Environmental Monitoring and Assessment, 184(10): 
1-9. doi: 10.1007/s10661-011-2388-9

Wang Shuying, Lu Ping, Wang Jianli et al., 2008. Spatial variability and distribution of soil organic matter and total nitrogen at different scales: A case study in Pinggu County, Beijing. Acta Ecologica Sinica, 28(10): 4957-4964. (in Chinese)

Xia X, Chen X, Liu R et al., 2011. Heavy metals in urban soils with various types of land use in Beijing, China. Journal of Hazardous Materials, 186(2-3): 2043-2050. doi: 10.1016/j. jhazmat.2010.12.104

Xu N Z, Liu H Y, Wei F et al., 2012. Urban expanding pattern and soil organic, inorganic carbon distribution in Shanghai, China. Environmental Earth Sciences, 66(4): 1233-1238. doi: 10.1007/s12665-011-1334-z
Yu D, Shi X, Wang H et al., 2007. Regional patterns of soil organic carbon stocks in China. Journal of Environmental Management, 85(3): 680-689. doi: 10.1016/j.jenvman.2006. 09.020

Zhang Ganlin, Zhu Yongguan, Fu Bojie, 2003. Quality changes of soils in urban and suburban areas and its eco-environmental impacts-A review. Acta Ecologica Sinica, 23(3): 539-546. (in Chinese)

Zhang Xinyu, Chen Liding, Fu Bojie et al., 2006. Soil organic carbon changes as influenced by different agricultural land use types and management practices: A case study in Yanqing Basin, Beijing. Acta Ecologica Sinica, 26(10): 3198-3204. (in Chinese) 